\title{
Nutrition education via "instagram" and motivational interviewing for weight loss motivation and physical activity in obese female students
}

\author{
${ }^{1}$ Amalia, M.S., ${ }^{1}$ Dieny, F.F., ${ }^{1,2, *}$ Candra, A., ${ }^{1}$ Nuryanto and ${ }^{1,2}$ Tsani, A.F.A \\ ${ }^{1}$ Department of Nutrition Science, Faculty of Medicine, Universitas Diponegoro, Semarang, Central Java \\ 50275, Indonesia \\ ${ }^{2}$ Center of Nutrition Research, Faculty of Medicine, Universitas Diponegoro, Semarang, Central Java \\ 50275, Indonesia
}

\begin{abstract}
Article history:
Received: 8 February 2021

Received in revised form: 19

March 2021

Accepted: 22 March 2021

Available Online: 28 July

2021
\end{abstract}

Keywords:

Instagram,

Nutrition education,

Motivational interviewing,

Weight loss,

Physical activity

DOI:

https://doi.org/10.26656/fr.2017.5(S3).004

\begin{abstract}
Nutrition education and motivational interviewing are methods to increase motivation, as essential factors in increasing physical activity. The purpose of this study was to determine the effect of nutrition education via Instagram and motivational interviewing, on weight loss motivation and physical activity of obese female students. This study was quasi-experimental with a pre-post-controlled group design that involved thirty-seven obese female students aged 18-23 years at Universitas Diponegoro, selected by proportional stratified sampling. Subjects were divided into three groups, P1 was given nutrition education via Instagram for 30 days (ED) and motivational interviewing four times (MI), P2 was given ED only, and the control (K) was given a leaflet. Weight loss motivation was measured using a healthy diet motivation questionnaire, and physical activity (PA) was measured using IPAQ-SF. Data were analyzed using one way ANOVA, Kruskal Wallis, paired t-test, Wilcoxon, and Mann Whitney. There was an increase in the mean of weight loss motivation that highest in group P1 (109.86 into 126.43), followed by group P2 (114.85 into 121.69) and group K (105.30 into 112.90). The highest increase in the mean of total physical activity was in the P1 group (1341 to 2572), the P2 group (1761 to 2378), and the $\mathrm{K}$ group decreased (3404 to 1987) in METs units. There was a significant difference in the mean change in total physical activity and moderate physical activity between $\mathrm{P} 1$ and $\mathrm{P} 2$ groups when compared to the K group.
\end{abstract}

\section{Introduction}

World Health Organization (WHO) recommended an accumulated 150-minute/week physical activities in moderate-intensity or an accumulated 75-minute/week in high-intensity. The lack of physical activity is when a person fails to meet the physical activity recommendation to improve or maintain body health. The Indonesian Ministry of Health reports show that as much as $33.5 \%$ of Indonesian people aged over 10-yearolds have low physical activity in 2018 (Ministry of Health Republic of Indonesia, 2018). Women tend to have lower physical activity when compared to men, and $32 \%$ of those are categorized as less active (Farradika et al., 2019). Lack of physical activity into the causes of obesity.

Obesity incidence increased three-fold from 1975 to 2016 with a percentage of $13 \%$ worldwide (World Health Organization (WHO), 2019). In Indonesia, the obesity incidence rate of over 18-year-olds tended to rise by $21.8 \%$, higher in $2013(14.8 \%)$, and 2010 (10.5\%), and occurred more in women. The increasing obesity rate trend is a challenge that is vital to conduct obesity handling efforts on women (Hamrik et al., 2014; Nho, 2017).

Women of Reproductive Age (WRA) with obese nutritional status are at risk of possessing breast cancer, cervix cancer, metabolic syndromes, and polycystic ovary syndrome (Brown, 2008). Obese WRAs also possess an infertility risk of three-fold higher than WRAs with normal nutritional status (Nho, 2017). One of the WRA groups susceptible to obesity is students because this phase addresses lifestyle changes (Kurniawan and Widyaningsih, 2017; Abraham et al., 2018). Approximately $60 \%$ and $38.3 \%$ of medical students in Universitas Brawijaya and Universitas Udayana, respectively, had low physical activities (Riskawati et al., 2018). These results are different from research that 
showed knowledge level affects the human lifestyle (Jaminah and Mahmudiono, 2018). Lack of knowledge about physical activity and healthy eating behaviours become obstacles in the implementation of healthy lifestyles. Nutrition education is a solution to overcome these obstacles.

Nutrition education is the provision of information covering dietary intake and physical activity under the guidelines for balanced nutrition. It aims to influence the subject's behaviour so that it is applied in their lives (Zaki and Sari, 2019). Nutrition education is carried out through several media and methods (Safitri and Fitranti, 2016). Tedious method utilization may provoke resistance to change on subjects (Zeidi and Hajiagha, 2013). Along with technological advances, developments were made for nutrition education media, from printed media, audio-visual, short message service (SMS), website, and social media. Intervention through social media on students may improve attitude, practice, and perception of physical activities and add insights regarding food material choices (Elmer et al., 2016; Hamadeh et al., 2019). Ease of access puts social media as an effective medium to deliver information (Cavallo et al., 2012).

Instagram is the second-leading popular social media after Facebook, with a significant increase of users that reached 60.97 million. Most of Instagram users (59\%) were 18-21-year-olds. One group in such an age range is students who have positive behaviour on brands on Instagram. Studies mentioned that as Instagram users, students tend to follow accounts they wish to follow the development (Rochman and Iskandar, 2015).

Instagram has a vision of "We bring you to the people and things that you love" that enables its users to see, share photos/videos and communicate through comments and direct messages (Cahya and Yulianto, 2018; Instagram, 2020). Instagram features to ease the delivery or acceptance of a message or material. The previous study on female adolescents showed that nutrition education provision based on social media of Instagram and WhatsApp could significantly increase subjects' nutrition knowledge (Zaki and Sari, 2019).

The motivation of conducting regular physical activities and a healthy diet is the key to obesity management, following changes in eating behaviour besides nutrition knowledge improvement (Gourlan et al., 2013). Motivational Interviewing (MI) is a collaborative discussion method between counsellors and clients that aims to strengthen the motivation and commitment to change through client-centred collaboration and autonomy (Miller and Rollnick, 2012; Hardcastle et al., 2013; Willis, 2017).
The American Heart Association recommends the MI method as a practical approach as the first step of weight loss. The provision of MI as an additional intervention in a weight loss program, for 4-5 times with 45-60 minutes duration, increases physical activities and brings success in losing weight (Carels et al., 2007). Another study stated that the MI intervention increased the mean of moderate and vigorous physical activities from 90.33 minutes to 213.5 minutes in the fourth month after the intervention (Mahmoodabad et al., 2017). The provision of MI to patients at risk of cardiovascular diseases increased walking activities, decreased diastolic blood pressure, and decreased cholesterol levels (Zaki and Sari, 2019).

Based on the background, few studies have been made that combine nutrition education methods via Instagram with motivational interviewing to improve weight loss and physical activities in obese women. Therefore, the authors were interested in conducting the present study to discover the effects of nutrition education via Instagram (ED) for consecutive 30 days with or without motivational interviewing (MI) on the weight loss motivation and physical activities on obese female students Universitas Diponegoro Semarang.

\section{Materials and methods}

\subsection{Design, location, time}

This study was included in public nutrition's scientific scope with a quasi-experimental design and a pre-post controlled group design. The study was conducted from June to September 2019 and took place at Universitas Diponegoro Semarang. This study obtained permission from the Health Research Ethics Committee Faculty of Medicine Universitas Diponegoro number 479/EC/KEPK/FK UNDIP/XI/2019.

\subsection{Subjects and sampling}

The subjects in this study were active students from non-health faculties, aged 18-23 years, had a nutritional status of obesity (BMI $\geq 25 \mathrm{~kg} / \mathrm{m}^{2}$ ), were not pregnant, injured, participated in educational programs or nutritional counselling from other parties, has an Instagram account and is an active user, and is willing to be a study subject by filling out an informed consent. The exclusion criteria were subjects who resigned during the intervention period, died, and did not fulfil the intervention for $100 \%$

The subjects in this study were selected using the proportional stratified sampling method according to the inclusion criteria. The sample size was calculated using paired numerical analysis. Forty-five subjects were obtained through the screening process; however, eight 
subjects dropped out so that the total subjects were 37 people. Furthermore, the subjects were divided into three groups, i.e., the first treatment group (P1) for 14 subjects, the second treatment group (P2) for 13 subjects, and the control group $(\mathrm{K})$ for 10 subjects. P1 group was given nutrition education and motivational interviewing and leaflet. $\mathrm{P} 2$ group was only given nutrition education and leaflet, while the $\mathrm{K}$ group was only given a leaflet containing information on balanced nutrition and the importance of maintaining body weight at the beginning of the study.

\subsection{Intervention}

\subsubsection{Nutrition education}

This study's independent variables were nutrition education via Instagram (ED) and motivational interviewing (MI). Nutrition education was provided through the@healthydietgizi Instagram account, with one topic per day for 30 consecutive days in the form of infographics. The @ healthydietgizi Instagram account is private and can only be followed by subjects in P1 and P2 groups. Apart from providing education, the authors also acted as an admin who managed the Instagram account. A total of three to four infographics were uploaded daily. The ED materials provided included obesity, planning, and recommendations for physical activities, sedentary lifestyle, and dietary patterns following balanced nutrition principles. Under the agreed agreement at the beginning of the study, the subject should leave likes and comments on each infographic uploaded. It aimed to ensure that the subject received and read every education given. Besides, the authors sent each new upload to the study subjects' personal Instagram account via direct messages to provide easy access.

\subsubsection{Motivational interviewing}

Motivational Interviewing is a collaborative discussion between the subject and the counsellor using the nutritional counselling method based on the Standardized Nutritional Care Process principles, which aims to strengthen the subject's motivation and be adjusted to the constraints of each subject (Hardcastle et al., 2013; Mirkarimi et al., 2015; Mahmoodabad et al., 2017). The MI was given by a nutritionist, with a frequency of 4 times for 45-60 minutes per individual for each meeting. The meeting was held on an agreed day between the subject and the nutritionist. This study's dependent variables were motivation to lose weight, total physical activities, walking activities, moderate physical activities, and vigorous physical activities.

\subsection{Research instrument}

Weight loss motivation was measured by the Healthy
Diet Motivation Questionnaire, a modified Behavioral Regulation in Exercise Questionnaire (BREQ-3) with the final result of a score (Cid et al., 2018; Sweeney et al., 2019). Based on $r$ calculation $>r$ table of 0.2159 and a Cronbach's Alpha value of 0.738 , Healthy Diet Motivation Questionnaire was valid and reliable (Sujarweni, 2014). Physical activities were measured using the International Physical Activity Questionnaire Short Form (IPAQ-SF) questionnaire and expressed in metabolic tasks per week (METs) (Rocha and Marega, 2010). Measurement of body weight and height. Body weighing was using a digital stepping scale with an accuracy of $0.1 \mathrm{~kg}$, and height was measured using a microtoise with an accuracy of $0.1 \mathrm{~cm}$ affixed to the wall.

\subsection{Data collecting and analysis}

The data collected were data on subjects' characteristics, motivation to lose weight, and physical activity. Subjects' characteristics data included name, age, weight, height, department, faculty, monthly allowances, current residence, WhatsApp number, and Instagram account. The age of the subject is the age from birth to the study conducted, measured in units of years. Allowance is subjects' money, whether it came from parents, scholarships, or side works to meet food and non -food needs per month, with a high category if $\geq$ IDR $1,000,000.00$ and low if $<$ IDR $1,000,000.00$ (Kurniawan and Widyaningsih, 2017).

Weight loss motivation is the drive that exists within a person to adopt an active lifestyle and eat healthy foods to lose weight as measured using the Healthy Diet Motivation questionnaire. Total physical activity is defined as all forms of subject activity that can expend energy and is measured once a week. The total physical activities consisted of walking, moderate physical activities, and vigorous physical activities (Gilbert et al., 2018). Walking activity is defined as walking for at least ten consecutive minutes measured for one week. Moderate physical activity is defined as activities that require a certain amount of effort and increase heart rate with a score of 3-6 METs covering badminton, swimming, playing golf, gardening, cycling at moderate speed, and daily homework. Vigorous physical activity is defined as physical activities that require significant effort and cause shortness of breath and increase heart rate by a score of $>6$ METs. Data were processed using Statistical Package for the Social Sciences (SPSS). Data analysis used the One-Way ANOVA test, Kruskal Wallis, Paired T-Test, Wilcoxon, and Mann Whitney (Dahlan, 2011). 


\section{Results}

Table 1 shows the characteristics of subjects. The subjects were 20 years old, with a mean Body Mass Index (BMI) of $28.5 \mathrm{~kg} / \mathrm{m} 2 \pm 2.7$. As many as $70.3 \%$ of study subjects were from Science and Technology, $67.6 \%$ resided in boarding houses, and $56.8 \%$ had monthly allowances of $<$ IDR $1,000,000$.

After conducting different tests on motivation to lose weight, total physical activities, walking activities, and vigorous physical activities, Table 2 summarises that there were no differences between the three groups at the beginning of the study. However, different tests on moderate physical activities show differences between the three groups at the beginning of the study. It can be caused by the division of the first treatment group, the second treatment, and the control group without paying attention to variations.
The analysis of before and after treatment in Table 2 showed a significant increase in the motivation variable to lose weight $(\mathrm{p} \leq 0.001)$, total physical activities ( $\mathrm{p}=$ $0.001)$, walking activities $(\mathrm{p}=0.024)$, and moderate physical activities $(\mathrm{p}=0.002)$ in the $\mathrm{P} 1$ group. Furthermore, there was no significant change in the P2 group. There was a significant increase in weight loss motivation $(\mathrm{p}=0.041)$ and a significant decrease in moderate physical activities $(\mathrm{p}=0.011)$ in the $\mathrm{K}$ group.

The difference analysis in the mean change in variables shows a significant difference in the variable total physical activities $(p=0.004)$ and moderate physical activities in the three groups $(p \leq 0.001)$. However, there were no significant difference in the mean changes in motivation to lose weight, walking activities, and vigorous physical activities in the three groups.

Table 1. Study subjects' characteristics

\begin{tabular}{llccccc}
\hline \multicolumn{1}{c}{ Variable } & \multicolumn{1}{c}{ Characteristic } & $\mathrm{n}$ & $\%$ & Mean $\pm \mathrm{SD}$ & Min & Max \\
\hline Age $($ years $)$ & & & & $20 \pm 1.17$ & 18 & 22 \\
BMI $\left(\mathrm{kg} / \mathrm{m}^{2}\right)$ & & & & $28.5 \pm 2.7$ & 25 & 37.5 \\
Faculty & Science and technology & 26 & 70.3 & & & \\
& Social sciences & 11 & 29.7 & & & \\
Residence & Rented rooms & 26 & 70.2 & & & \\
& House & 11 & 29.7 & & & \\
Allowance & $\geq$ IDR1,000,000.00 & 16 & 43.2 & & & \\
& LIDR1,000,000.00 & 21 & 56.8 & & & \\
\hline
\end{tabular}

Table 2. Differences in weight loss motivation; total, walking, moderate, and vigorous PA

\begin{tabular}{|c|c|c|c|c|}
\hline Variable & $\mathrm{P} 1$ & $\mathrm{P} 2$ & $\mathrm{~K}$ & $\operatorname{sig}(p)$ \\
\hline \multicolumn{5}{|l|}{ Weight loss motivation (score) } \\
\hline Before & $109.86 \pm 10.3$ & $114.85 \pm 16.5$ & $105.30 \pm 13.6$ & $0.260^{\mathrm{a}}$ \\
\hline After & $126.43 \pm 11.5$ & $121.69 \pm 16.6$ & $112.90 \pm 13.3$ & \\
\hline$p$ & $<0.001^{\mathrm{c} *}$ & $0.056^{\mathrm{c}}$ & $0.041^{\mathrm{c} *}$ & \\
\hline$\Delta$ Motivation to lose weight & $16.5 \pm 13.1$ & $6.8 \pm 11.6$ & $7.6 \pm 10.0$ & $0.079^{\mathrm{a}}$ \\
\hline \multicolumn{5}{|l|}{ Total PA (METs) } \\
\hline Before & $1341 \pm 947$ & $1761 \pm 1553$ & $3404 \pm 2394$ & $0.095^{\mathrm{b}}$ \\
\hline After & $2572 \pm 1934$ & $2378 \pm 1680$ & $1987 \pm 1659$ & \\
\hline$p$ & $0.001 \mathrm{~d}^{*}$ & $0.131^{\mathrm{d}}$ & $0.066^{\mathrm{d}}$ & \\
\hline$\Delta$ Total PA & $1231 \pm 1237$ & $617 \pm 1914$ & $-1417 \pm 2067$ & $0.004^{\mathrm{b} *}$ \\
\hline \multicolumn{5}{|l|}{ Walking PA (METs) } \\
\hline Before & $445 \pm 726$ & $198 \pm 323$ & $830 \pm 1455$ & $0.260^{\mathrm{b}}$ \\
\hline After & $701 \pm 1088$ & $410 \pm 432$ & $737 \pm 1435$ & \\
\hline$p$ & $0.024^{\mathrm{d} *}$ & $0.074^{\mathrm{d}}$ & $0.953^{\mathrm{d}}$ & \\
\hline$\Delta$ Walking PA & $256 \pm 754$ & $213 \pm 441$ & $-93 \pm 496$ & $0.326^{\mathrm{b}}$ \\
\hline \multicolumn{5}{|l|}{ Moderate PA (METs) } \\
\hline Before & $593 \pm 551$ & $984 \pm 757$ & $1938 \pm 1156$ & $0.008^{\mathrm{b} *}$ \\
\hline After & $1562 \pm 1502$ & $1657 \pm 1700$ & $989 \pm 852$ & \\
\hline$p$ & $0.002^{\mathrm{d} *}$ & $0.05^{\mathrm{d}}$ & $0.011^{\mathrm{d} *}$ & \\
\hline$\Delta$ Moderate PA & $970 \pm 1449$ & $673 \pm 1440$ & $-949 \pm 1048$ & $<0.001^{\mathrm{b} *}$ \\
\hline \multicolumn{5}{|l|}{ Vigorous PA (METs) } \\
\hline Before & $302 \pm 633$ & $593 \pm 1627$ & $636 \pm 1211$ & $0.907^{b}$ \\
\hline After & $333 \pm 503$ & $322 \pm 470$ & $260 \pm 310$ & \\
\hline$p$ & $0.43^{\mathrm{d}}$ & $0.386^{\mathrm{d}}$ & $0.310^{\mathrm{d}}$ & \\
\hline$\Delta$ Vigorous PA & $30 \pm 756$ & $-272 \pm 1735$ & $-375 \pm 994$ & $0.485^{\mathrm{b}}$ \\
\hline
\end{tabular}


The mean significant changes in the variable total physical activities and moderate physical activities indicate that at least two groups were significantly different. Furthermore, the Mann Whitney test was conducted to determine which group experienced this significant difference. Based on Table 3, it is discovered that there was a significant difference in the mean change in total physical activities and moderate physical activities. This significant difference occurred in the P1 group when compared to the $\mathrm{K}$ group, and the $\mathrm{P} 2$ group when compared to $\mathrm{K}$. There was no significant difference in the $\mathrm{P} 1$ group when compared to $\mathrm{P} 2$.

Table 3. Differences in mean changes of total and moderate PA on the three groups

\begin{tabular}{lccc}
\hline \multirow{2}{*}{ Variable } & P1-P2 & P1-K & P2-K \\
\cline { 2 - 4 } & $\operatorname{sig}(p)$ & $\operatorname{sig}(p)$ & $\operatorname{sig}(p)$ \\
\hline$\Delta$ Total PA (MET) & $0.286^{\mathrm{a}}$ & $0.002^{\mathrm{a} *}$ & $0.015^{\mathrm{a} *}$ \\
$\Delta$ Moderate PA & $0.437^{\mathrm{a}}$ & $<0.001^{\mathrm{a} *}$ & $0.001^{\mathrm{a} *}$ \\
\hline
\end{tabular}

${ }^{\mathrm{a}}$ Mann Whitney test

*significant

\section{Discussion}

Students have an important role in social life because they can influence the next generation through their knowledge and experiences as educated individuals. This period is a transitional period that requires the subject to make decisions independently. Health behaviour is one pattern of life formed during this period. However, based on previous studies, students were included in the group that is susceptible to a sharp decrease in physical activity. This behaviour would continue, and it was difficult to change once it is started (Abraham et al., 2018; Aleksovska-velickovska et al., 2019). Based on their age, students were included in the category of Women of Reproductive Age (WRA). They are women of 15-49-year-olds who have mature and functioning reproductive organs. The decrease in physical activities over a long time can lead to obesity. Obesity occurs due to a positive energy balance that lasts for a long time, and thus, the body experiences large amounts of fat accumulation (Dieny, 2014; Noer et al., 2018).

A total of 45 female students were obtained through the screening stage. However, eight people dropped out, and therefore the subjects studied were thirty-seven $(\mathrm{n}=$ 37) people. The causes were that four people resigned, three people could not be contacted again during the intervention period, and one person had incomplete data. Subjects were obese female students with a mean age of 21 years, with a mean BMI of $28.5 \pm 2.7 \mathrm{~kg} / \mathrm{m}^{2}$. Thus, subjects were included in the category of Women of Reproductive Age (WRA). As many as $70.3 \%$ of subjects came from the faculty of sciences and technology (Science and technology), 67.6\% of subjects resided in boarding houses, and $56.8 \%$ of subjects had an allowance of $<$ IDR 1,000,000.00 per month.

At the beginning of the study, the results of the analysis show that there were no significant differences in the motivation variables to lose weight, walking, vigorous physical activities, and total physical activities. It shows that the three groups were in the same condition at the beginning. However, there was a significant difference in the moderate physical activities variable before the intervention.

\subsection{Changes in motivation to lose weight}

Before the intervention, the $\mathrm{P} 2$ group had the highest motivation score to lose weight, and the $\mathrm{K}$ group had the least score. However, a significant increase in weight loss motivation occurred in the $\mathrm{P} 1$ group compared to the $\mathrm{P} 2$ and $\mathrm{K}$ groups. The increase in weight loss motivation in the P1 group was due to nutritional education provision for 30 consecutive days via Instagram, accompanied by motivational interviewing four times, which was conducted once a week. The previous study showed that MI could increase an individual's motivation to fight barriers, the ability to care for oneself and strengthen a willingness to adopt a healthy lifestyle (Lin et al., 2016).

After the intervention, there was an increase in weight loss motivation in the P2 group, but it was not significant. This finding is following a study by Barnes et al. (2018) which provided five interventions for MI and Nutrition Psychoeducation (MINP) with a duration of 20 minutes per session, showing that there was no significant change in individual motivation to lose weight. It was because subjects already had the motivation to undergo a weight loss program, and hence, subjects felt satisfied with the treatment undertaken before (Barnes et al., 2018).

The choice food types consumed shows an increase in fruit and vegetable intakes and a decrease in the highfat food intake that could be caused by an increase in motivation to be healthy eating (Naughton et al., 2015). Based on the previous study, subjects who put health factors as the main reason for diet tended to perceive that the lifestyle, they have applied so far was good. This results in the assumption that the interventions provided did not provide more benefits. Another factor that can cause an insignificant increase in dietary motivation in this study was food selection considerations such as price, sensory appeal (colour, aroma, taste), and natural food content (Rankin et al., 2018).

There was an increase in the motivation score to lose weight significantly in the $\mathrm{K}$ group after giving the 
intervention. $\mathrm{K}$ group experienced a change in score (7.6 \pm 10.0$)$, which was higher than the P2 group score $(6.8 \pm 11.6)$ but lower than the score for the P1 group (16.5 \pm 13.1$)$. However, the motivation score for weight loss in the $\mathrm{k}$ group $(112.9 \pm 13.3)$ was lower when compared to the score for the $\mathrm{P} 1$ group $(126.4 \pm 11.5)$ and the score for the P2 group (121.69 \pm 16.6$)$. One factor that led to an increase in the motivation score to lose weight in the $\mathrm{K}$ group was the leaflet's provision to increase personal knowledge and attitudes (Meidiana et al., 2018). The leaflet contained information on balanced nutrition and the importance of maintaining body weight. Good nutritional knowledge is a strengthening factor in implementing a healthy lifestyle, allowing an increased weight loss motivation in the $\mathrm{K}$ group.

\subsection{Changes in physical activities}

The promotion of physical activities becomes a big challenge when carried out on specific groups, where women with obese nutritional status are one of them. Obese women have a more significant barrier than women with normal nutritional status at the same age due to society's social stigma. Based on a previous study conducted on women of 18-55-year-olds using the focus group discussion (FGD) method, there were three main obstacle factors in carrying out physical activities, i.e., intrapersonal barriers $(51.3 \%)$, environmental barriers $(32.1 \%)$, and interpersonal barrier $(16.6 \%)$. Regarding this study, motivational interviewing was provided as a form of support for the subjects, thereby reducing barriers to physical activities (Mcintosh et al., 2016).

Before the intervention was given, the mean subjects' physical activity on the K group (3404 \pm 2394 METs) was the highest than P2 $(1761 \pm 1553$ METs $)$ and P1 (1341 \pm 947 METs) groups. However, the increased mean physical activity was the highest in the P1 group, followed by the $\mathrm{P} 2$ group, while the $\mathrm{K}$ group experienced a decrease after the intervention. Physical activities increase in $\mathrm{P} 1$ and $\mathrm{P} 2$ groups because they provide nutritional education via Instagram for 30 consecutive days. An adequate and repetitive education provision may change an unhealthy lifestyle into the healthy one, though this process needs a long time (Mahmoodabad et al., 2017).

Besides education, the $\mathrm{P} 1$ group was also provided with MI four times by a nutritional expert. The finding follows the previous study, where MI was proven to increase physical activities (Lin et al., 2016). The same result was also discovered in a study by Mahmoodabad et al., 2017 showing that MI intervention prevention using the Self Determination Theory (SDT) framework may increase physical activities significantly on Women of Reproductive Age after the intervention and four months post-intervention. On the other hand, the decreasing mean physical activities in the $\mathrm{K}$ group caused by the absence of special monitoring, limited time to perform physical activities, and decreased in all types of physical activities.

Based on Lawrence Green's theory, humans' behaviours are influenced by two primary factors, i.e., behaviour and off-behaviour. Then, three primary factors shape humans' behaviours, i.e., predisposition, enabling, and strengthening. The ED and MI provisions by counsellors were predisposition factors, marked by an increased weight loss motivation that increased physical activities in P1. Counsellors' attitude in providing support through motivational interviewing could be the strengthening factor for subjects to apply higher physical activities than before (Notoatmodjo, 2010).

Before the intervention, the highest walking activity was in the K group ( $830 \pm 1455$ METs) compared to the P1 (445 \pm 726 METs) and P2 (198 \pm 323 METs) groups. After the intervention, it is discovered that there were no significant differences between walking activities in all three groups. However, the P1 group experienced a significant increase from the mean walking activity value, followed by the $\mathrm{P} 2$ group, which also increased insignificantly. In contrast, the $\mathrm{K}$ group experienced a decrease in the mean walking activity.

The significant increase in mean walking activity of the P1 group follows the previous study that mentioned that motivational interviewing provision increased walking and decreased cholesterol significantly (Hardcastle et al., 2013). Nutrition education provision related to walking activities, tips for a fun walk, and invitations to walk from Instagram were also strengthening factors causing increased walking activities in the $\mathrm{P} 1$ and $\mathrm{P} 2$ groups.

Compared to other physical activities, walking is comfortable, light, practical, and free to perform. Walking activities were often carried out by the P1 and P2 groups as a means of transportation to the campus and sports. The Universitas Diponegoro area had a walkability value of 66.71, which included in the yellow category, or good enough to walk. Therefore, walking activities around campus are an appropriate choice (Tanan et al., 2017).

However, in Indonesia, the average walking activity is $<3500$ steps per day and is included in the country's category with a low walking activity (Althoff et al., 2017). The decrease of walking activity in the $K$ group might be caused by several factors such as the distance between residence and campus, tendency to utilize motor vehicles, limited time, and high temperature in Semarang 
(Tanan et al., 2017).

Before the intervention, the mean moderate-intensity physical activity was the highest on the $\mathrm{K}$ group (1938 \pm 1156 METs), followed by the P2 (984 \pm 757 METs) and P1 $(593 \pm 551$ METs $)$ groups. Preintervention data show that all three groups were not homogeneous. That condition caused limitations in the study. Therefore, the three groups' significant mean changes might be caused by varying data between the three groups. Nevertheless, based on the Paired-T test, it is discovered that the P1's moderate-intensity physical activity was increasing significantly. The $\mathrm{P} 2$ group was also increasing although insignificant, while the $\mathrm{K}$ group was experiencing a significant decrease.

The significant increase in the $\mathrm{P} 1$ group was following previous studies which stated that giving MI by telephone for 12 weeks with a duration of 15-30 minutes per subject was able to increase moderate physical activities (Lin et al., 2016). The types of moderate physical activities conducted by subjects were washing clothes, sweeping, and mopping the floor. The ease of access to subjects in carrying out moderate activities caused a behaviour change. The theory of Response Organism Stimulus (SOR) explains that behaviour change can be realized when the existing stimulus is received and can convince subjects, and therefore, attitude changes occur. Attitude changes that are supported by the environment will result in a behaviour change. The provision of ED + MI and ED interventions in this study acted as stimulation in the P1 and P2 groups (Notoatmodjo, 2010).

A significant decrease in moderate physical activities in the $\mathrm{K}$ group was made possible by several subjects who were doing temporary, moderate physical activities only at one time. It caused a significant difference in the mean moderate physical activities at the beginning and the end of the study. The types of moderate physical activities conducted by subjects were badminton and cycling with moderate intensity.

Before the intervention, the highest vigorous intensity was provided by the $\mathrm{K}$ group $(636 \pm 1211$ METs) compared to the P2 (593 \pm 1627 METs $)$ and P1 (302 \pm 633 METs) groups. However, the increase only occurred in the $\mathrm{P} 1$ group, while the $\mathrm{P} 2$ and $\mathrm{K}$ groups decreased after the intervention. Vigorous physical activities such as swimming, basketball, volleyball, running, and fast cycling require facilities and infrastructure, but not all subjects had this access. Facilities and infrastructure in carrying out vigorous physical activities were significant obstacles faced by subjects. In line with previous studies, sports facilities had a strong relationship with the subjects' physical activity. Subjects who had no access to sports facilities tended to be less active (Farradika et al., 2019).

Based on the theory of behaviour change of Kurt Lewin, behaviour change occurs due to an imbalance between the reinforcement strength, which is greater than the holding strength (Notoatmodjo, 2010; Ranitadewi et al., 2018). The strengthening factor was obtained by subjects in the form of support by counsellors to subjects to do physical activities, which had a more significant impact than the obstacles, increased vigorous physical activities in the P1 group. The strengthening factors in the form of ED and leaflet delivery could not exceed the obstacles in carrying out vigorous physical activities in the $\mathrm{P} 2$ and $\mathrm{K}$ groups so that no change in vigorous physical activity was achieved. Motivational interviewing can be given with a frequency of more than four meeting sessions, and it is necessary to increase the duration of nutrition education via Instagram and motivational interviewing for more than two months (Mirkarimi et al., 2015; Barnes et al., 2018).

Based on different tests for each group, the nutrition education via Instagram collaborated with motivational interviewing, show a significant difference in the motivation to lose weight, total physical activities, walking, and moderate physical activities. Nutrition education only via Instagram did not show a significant difference in the mean weight loss motivation and the mean physical activities. The control group given leaflets showed a significant increasing difference in the mean weight loss motivation and a significant decrease in the mean of moderate physical activities.

After conducting different tests between the three groups, there were significant differences in the mean change in total physical activities and moderate physical activities. There were no significant differences in motivation changes to lose weight, walking activities, and vigorous physical activities between the three groups. The significant differences in the mean change in total physical activities and moderate physical activities were further tested using the Mann Whitney test. The test results show significant differences in the mean change in total physical activities and physical activities between the $\mathrm{P} 1$ and $\mathrm{P} 2$ groups compared to the $\mathrm{K}$ group.

\section{Conclusion}

This study provides evidence that nutrition education via Instagram collaborated with motivational interviewing increases the total physical activities that encouraged weight loss in obese women. 


\section{Conflict of interest}

The authors declare no conflict of interest.

\section{Acknowledgments}

This research was funded by the Development and Application Research by Universitas Diponegoro in 2019. The authors express gratitude to all faculties at Universitas Diponegoro, who participated in this study and supervisors and examiners who have provided support until the study is well-completed.

\section{References}

Abraham, S., Noriega, B.R. and Shin, J.Y. (2018). College students eating habits and knowledge of nutritional requirements. Journal of Nutrition and Human Health, 2(1), 13-17. https://doi.org/10.35841/ nutrition-human-health.2.1.13-17

Aleksovska-Velickovska, L., Gontarev, S. and Ruzdija, K. (2019). Students motivation for engaging in physical activity: Theory for self-determination. Journal of Human Sport and Exercise, 14(1), 325334. https://doi.org/10.14198/jhse.2019.142.06

Althoff, T., Hicks, J.L., King, A.C., Delp, S.L. and Leskovec, J. (2017). Large-scale physical activity data reveal worldwide activity inequality. Nature, 547(7663), 336-339. https:// doi.org/10.1038/nature23018

Barnes, R.D., Ivezaj, V., Martino, S., Pittman, B.P., Paris, M. and Grilo, C.M. (2018). Examining motivational interviewing plus nutrition psychoeducation for weight loss in primary care. Journal of psychosomatic research, 104(1), 101 $-107$. https://doi.org/10.1016/ j.jpsychores.2017.11.013

Brown, E.J. (2008). Preconception Nutrition: Condition and Interventions. In Adams, P. (Ed). Nutrition Through the Life Cycle 3rd ed, p. 67-69. California, USA: Wadsworth.

Cahya, S.B. and Yulianto, M. (2018). Use of Instagram social media in the formation of youth self identity. Online Interaction, 6(1), 490-501.

Carels, R., Darby, L., Cacciapaglia, H., Konrad, K. and Coit, C. (2007). Using motivational interviewing as a supplement to obesity treatment: a stepped-care approach. Health Psychology, 26(1), 369-374. https://doi.org/10.1037/0278-6133.26.3.369

Cavallo, D.N., Tate, D.F., Ries, A.V., Brown, J.D., DeVellis, R.F. and Ammerman, A.S. (2012). A social media-based physical activity intervention: a randomized controlled trial. American Journal of Preventive Medicine, 43(5), 527-532. https:// doi.org/10.1016/j.amepre.2012.07.019

Cid, L., Monteiro, D., Teixeira, D., Teques, P., Alves, S., Moutão, J., Silva, M. and Palmeira, A. (2018). The behavioral regulation in exercise questionnaire (BREQ-3) Portuguese-version: evidence of reliability, validity and invariance across gender. Frontiers in Psychology, 9(1), 1940. https:// doi.org/10.3389/fpsyg.2018.01940

Dahlan, M.S. (2011). Medicine and health statistic. 5th ed. Jakarta, Indonesia: Salemba Medika.

Dieny, F.F. (2014). Nutritional Problems in Young Women. 1st ed. Yogyakarta, Indonesia: Graha Ilmu.

Elmer, S.R., Harrison, J.A. and da Silva, V.R. (2016). Social media as a supplement to face-to-face education: The perspectives of expanded food and nutrition education program paraprofessionals and graduates. Journal of Extension, 54(3), 1-11.

Farradika, Y., Umniyatun, Y., Nurmansyah, M.I. and Jannah, M. (2019). Physical activity behavior and its determinant in the Faculty of Science - Health Sciences University of Muhammadiyah Prof. Dr. Hamka. Arkesmas, 4(1), 134-142. https:// doi.org/10.22236/arkesmas.v4i1.3548

Gilbert, A.L., Lee, J., Ehrlich-Jones, L., Semanik, P.A., Song, J., Pellegrini, C. A., Pinto Pt, D., Dunlop. D.D. and Chang, R.W. (2018). A randomized trial of a motivational interviewing intervention to increase lifestyle physical activity and improve self-reported function in adults with arthritis. Seminars in Arthritis and Rheumatism, 47(5), 732-740. https:// doi.org/10.1016/j.semarthrit.2017.10.003

Gourlan, M., Sarrazin, P. and Trouilloud, D. (2013). Motivational interviewing as a way to promote physical activity in obese adolescents: a randomisedcontrolled trial using self-determination theory as an explanatory framework. Psychology and Health, 28 (11), 1265-1286. https:// doi.org/10.1080/08870446.2013.800518

Hamadeh, S., Marquis, M. and Estepan, S. (2019). Tenpoint Vision Strategies to Offer a Menu of Options to Promote Healthy Eating and Active Living in Lebanon: Between Facts and Stories.

Hamrik, Z., Sigmundová, D., Kalman, M., Pavelka, J. and Sigmund, E. (2014). Physical activity and sedentary behaviour in Czech adults: results from the GPAQ study. European Journal of Sport Science, 14 (2), 193-198. https:// doi.org/10.1080/17461391.2013.822565

Hardcastle, S.J., Taylor, A.H., Bailey, M.P., Harley, R.A. and Hagger, M.S. (2013). Effectiveness of a motivational interviewing intervention on weight loss, physical activity and cardiovascular disease risk 
factors: a randomised controlled trial with a 12month post-intervention follow-up. International Journal of Behavioral Nutrition and Physical Activity, 10, 40. https://doi.org/10.1186/1479-5868$10-40$

Instagram. (2020). About Instagram. Retrieved on April 14, 2020 from Instagram Website https:// about.instagram.com/about-us.

Jaminah, J. and Mahmudiono, T. (2018). The Relationship between Knowledge and Physical Activity with Obesity in The Female Worker. Periodical Journal of Epidemiology, 6(1), 9 -17. https://doi.org/10.20473/jbe.V6I12018.9-17

Kurniawan, M. and Widyaningsih, T. (2017). Hubungan Pola Konsumsi Pangan dan Besar Uang Sakuu Mahasiswan Manajemen Bisnis dengan Mahasiswa Jurusan Teknologi Hasil Pertanian Universitas Brawijaya terhadap Status Gizi. Jurnal Pangan dan Agroindustri, 5(1), 1-12.

Lin, C.H., Chiang, S.L., Heitkemper, M.M., Hung, Y.J., Lee, M.S., Tzeng, W.C. and Chiang, L.C. (2016). Effects of telephone-based motivational interviewing in lifestyle modification program on reducing metabolic risks in middle-aged and older women with metabolic syndrome: A randomized controlled trial. International Journal of Nursing Studies, 60, 12-23. https://doi.org/10.1016/j.ijnurstu.2016.03.003

Mahmoodabad, S.S.M., Tonekaboni, N.R., Farmanbar, R., Fallahzadeh, H. and Kamalikhah, T. (2017). The effect of motivational interviewing-based intervention using self-determination theory on promotion of physical activity among women in reproductive age: a randomized clinical trial. Electronic Physician, 9(5), 4461-4472. https:// doi.org/10.19082/4461

Mcintosh, T., Hunter, D.J. and Royce, S. (2016). Barriers for physical activity in overweight adults. Brazilian Journal of Physical Activity and Health, 21(3), 27280. https://doi.org/10.1177/1744987116647762

Meidiana, R., Simbolon, D. and Wahyudi, A. (2018). Pengaruh Edukasi Media Audio Visual terhadap Pengetahuan dan Sikap Remaja Overweight. Jurnal Kesehatan, 9, 478-484. https://doi.org/10.26630/ jk.v9i3.961 [In Bahasa Indonesia].

Miller, W.R. and Rollnick, S. (2012). Motivational Interviewing: Helping people change. 3rd ed. New York: The Guilford Press. https://doi.org/10.5195/ MITRIP.2012.10

Ministry of Health Republic of Indonesia. (2018). Basic Health Research. Jakarta, Indonesia: Indonesian Ministry of Health Research and Development Center.
Mirkarimi, K., Mostafavi, F., Eshghinia, S., Vakili, M.A., Ozouni-Davaji, R.B. and Aryaie, M. (2015). Effect of motivational interviewing on a weight loss program based on the protection motivation theory. Iranian Red Crescent Medical Journal, 17 (6), 1-12. https://doi.org/10.5812/ircmj.23492v2

Naughton, P., McCarthy, S.N. and McCarthy, M.B. (2015). The creation of a healthy eating motivation score and its association with food choice and physical activity in a cross sectional sample of Irish adults. International Journal of Behavioral Nutrition and Physical Activity, 12(1), $74 . \quad$ https:// doi.org/10.1186/s12966-015-0234-0

Nho, J.H. (2017). Lifestyle intervention for obese women. Journal of Lifestyle Medicine, 7(2), 51. https://doi.org/10.15280/jlm.2017.7.2.51

Noer, E.R., Kustanti, E.R. and Fitriyanti, A.R. (2018). Nutritional behavior and psychosocial factors for obese adolescents. The Indonesian Journal of Nutrition, 6, 109-113. https://doi.org/10.14710/ jgi.6.2.109-113

Notoatmodjo, S. (2010). Health Behavioural Science. 1st ed. Jakarta, Indonesia: Rineka Cipta.

Ranitadewi, I.N., Syauqi, A. and Wijayanti, H.S. (2018). The effect of providing nutritional counseling on the percent body fat of overweight and obese women in pilates exercise participants. Journal of Nutrition College, 7, 123-132. https://doi.org/10.14710/ jnc.v7i3.22271

Rankin, A., Bunting, B.P., Poínhos, R., van der Lans, I.A., Fischer, A.R., Kuznesof, S., Almeida, M., Markovina, J., Frewer, L.J. and Stewart-Knox, B.J. (2018). Food choice motives, attitude towards and intention to adopt personalised nutrition. Public Health Nutrition, 21(14), 2606-2616. https:// doi.org/10.1017/S1368980018001234

Riskawati, Y.K., Prabowo, E.D. and Al Rasyid, H. (2018). Tingkat akitivitas fisik mahasiswa program studi Pendidikan dokter tahun kedua, ketiga, keempat. Majalah Kesehatan Fakultas Kedokteran, 5, 26-32. https://doi.org/10.21776/ ub.majalahkesehatan.005.01.4 [In Bahasa Indonesia].

Rocha, A.S. and Marega, M. (2010). The impact of motivational interventions for increasing physical activity. Einstein (São Paulo), 8(1), 46-52. https:// doi.org/10.1590/s1679-45082010ao1442

Rochman, E.A. and Iskandar, B.P. (2015). Users' engagement toward the brand accounts in instagram based on the AISAS model. Journal of Business and Management, 4(8), 890-900.

Safitri, N.R.D. and Fitranti, D.Y. (2016). The effect of 
nutrition education with lectures and booklets on increasing nutritional knowledge and attitudes of overweight adolescents. Journal of Nutrition College, 5, 374-380.

Sujarweni, W. (2014). Research methodology: Complete, practical and easy to understand. Yogyakarta: Pustakabaru press.

Sweeney, A.M., Wilson, D.K. and Brown, A. (2019). A qualitative study to examine how differences in motivation can inform the development of targeted physical activity interventions for African American women. Evaluation and Program Planning, 77, $101718 . \quad$ https://doi.org/10.1016/ j.evalprogplan.2019.101718

Tanan, N., Wibowo, S.S. and Tinumbia, N. (2017). Walkability index measurement on road links in urban area. Jurnal Jalan-Jembatan, 34, 115-127. [In Bahasa Indonesia].

World Health Organization (WHO). (2019). Obesity and Overweight. Retrieved on September 17, 2019 from WHO https://www.who.int/news-room/fact-sheets/ detail/obesity-and-overweight

Willis, S.S. (2017). Individual Counselling, Theory and Practice. 9th ed. Bandung: Alfabeta.

Zaki, I. and Sari, H.P. (2019). Social media-based nutrition education improves knowledge and energy - protein intakes of adolescent girl with chronic energy deficiency (CED). Journal of The Indonesian Nutrition Association, 42(2), 111-122. https:// doi.org/10.36457/gizindo.v42i2.469

Zeidi, I.M. and Hajiagha, A.P. (2013). Effect of motivational interviewing on eating habits and weight losing among obese and overweight women. Journal of Obesity and Weight Loss Therapy, 3, 172 . https://doi.org/10.4172/21657904.1000172 